\title{
Il Rene Policistico: una malattia non più senza speranze
}

Tutti noi constatiamo che, soprattutto negli ultimi anni, la medicina ha compiuto dei progressi enormi. Questo vale per tutte le discipline mediche: oggi è possibile formulare una diagnosi sempre più accurata grazie anche ad apparecchiature radiologiche sempre più sofisticate, le terapie sono sempre più mirate e gli stessi interventi chirurgici sono diventati sempre meno invasivi e demolitivi con tempi di recupero sempre più brevi. Inoltre alcune patologie prima assolutamente incurabili incominciano ad essere passibili di trattamenti; il Rene Policistico (APKD) è una di queste. Fino a pochi anni orsono, di fronte a un paziente affetto dalla presenza di cisti renali bilaterali, potevamo soltanto procedere a una diagnosi più circostanziata $\mathrm{e}$, se il sospetto veniva confermato, di fronte alla malattia APKD, con molto tatto dovevamo trovare le parole più adatte per spiegare al paziente una terribile verità: la ineluttabile progressione verso una insufficienza renale terminale che avrebbe richiesto il trattamento dialitico. Oggi non è più così o ci sono le premesse perché non sia più così. Grazie ad alcune fondamentali ricerche condotte in diversi laboratori abbiamo compreso i processi che sono alla base della formazione $\mathrm{e}$ della crescita delle cisti renali. Scoperti i meccanismi sono stati individuati anche farmaci in grado di interferire con la secrezione di liquido allinterno delle cisti. Studi preliminari sembrano confermare queste iniziali osservazioni. Tuttavia, prima che ci sia una diffusione su larga scala di questi farmaci, bisognerà attendere le conclusioni degli studi, ma le speranze sono fondate. Anche per i pazienti con $\mathrm{APKD}$ il futuro non è più così incerto.

Giovambattista Capasso Cattedra di Nefrologia, Seconda Università di Napoli gb.capasso@unina2.it

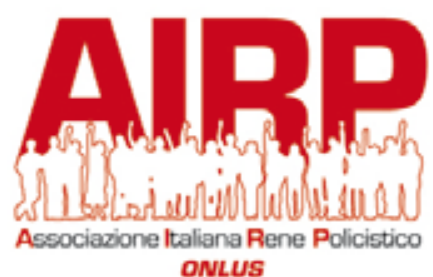

Sostieni la ricerca con il 5 per mille
Con la prossima dichiarazione dei redditi potrai devolvere il 5 per mille dell'IRPEF all' AIRP

Associazione Italiana Rene Policistico Onlus.

Non costa nulla e non è un'alternativa all'8 per mille

\section{Inserisci il codice fiscale dell'AIRP 97422810156 e ricordati di firmare}

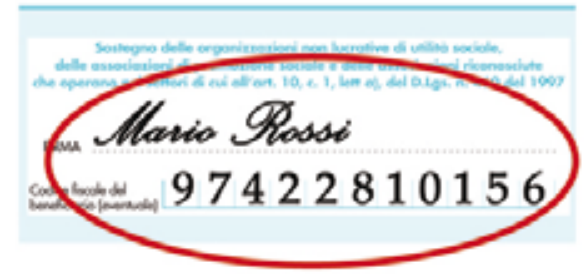

AIRP - Associazione Italiana Rene Policistico (ONLUS)

Sede Legale: Via Garofalo, 31 - 20133 MILANO - CF 97422810156 - Tel: +39 3342490433 - Fax: 1782755791 e-mail: info airp@renepolicistico, it - web: http://www.renepolicistico.it 